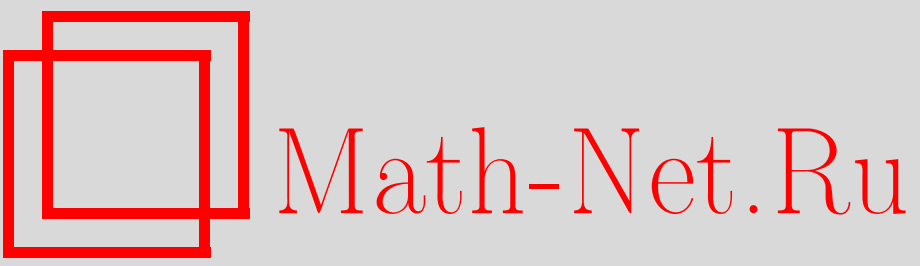

В. С. Владимиров, А. А. Дезин, А. А. Карацуба, Л. Д. Кудрявцев, М. П. Минеев, С. М. Никольский, Л. П. Постникова, Ю. В. Прохоров, В. Н. Чубариков, А. Б. Шидловский, А. А. Юдин, Алексей Георгиевич Постников (некролог), УМH, 1998, том 53, выпуск 1, 202-206

DOI: https://doi.org/10.4213/rm3

Использование Общероссийского математического портала Math-Net.Ru подразумевает, что вы прочитали и согласны с пользовательским соглашением http: //www . mathnet.ru/rus/agreement

Параметры загрузки:

IP : 54.80 .73 .141

26 апреля 2023 г., 17:30:09 


\section{АЛЕКСЕЙ ГЕОРГИЕВИЧ ПОСТНИКОВ}

Русский математик Алексей Георгиевич Постников завершил свой земной путь 22 марта 1995 года на 74 году жизни. Он родился в православной семье 12 июня 1921 года в Москве.

Прадедом Алексея Георгиевича по отцовской линии был Егор Васильевич Амфитеатров (1815-1888), о котором в Полном православном богословском энциклопедическом словаре сказано, что он окончил Петербургскую духовную академию, состоял по кафедре словесности профессором, в 1873 году избран Городским головой Сергиева Посада и скончался в чине действительного статского советника. Дед Алексея Георгиевича Василий Иванович Постников был священником. О нем в своих воспоминаниях епископ Арсений (Жадановский) пишет: “Отец Василий Постников по справедливости может считаться лучшим представителем московского духовенства. Он был просвещенньм талантливым человеком, хорошим проповедником, а главное высоконастроенным усердным служителем алтаря Господня, каким и должен быть пастырь столицы”. Отец, Георгий Васильевич Постников, окончил юридический факультет Московского университета и работал в Высшем совете народного хозяйства. Его арестовали в первый раз в 1929 г., во

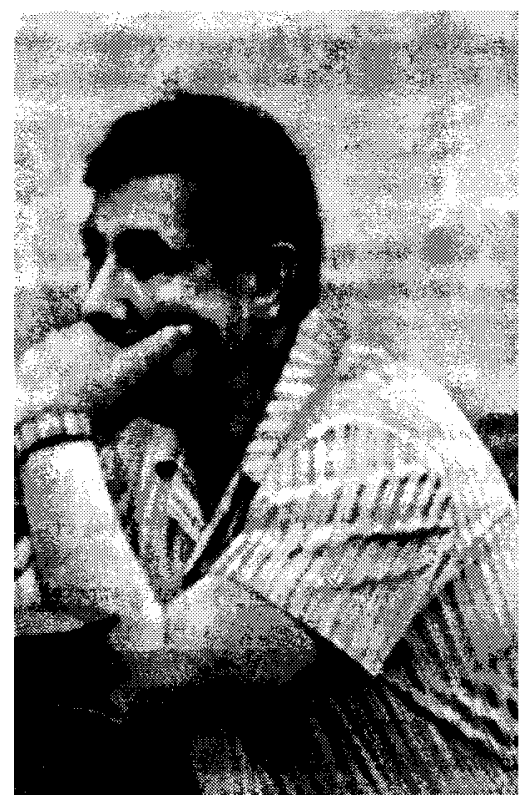
второй раз - в 1938 году, в 1956 году он был посмертно реабилитирован. Мать была старшей дочерью купца второй гильдии Семена Алексеевича Богомолова.

В 1931 году Алеша Постников пошел в школу № 59 г. Москвы, сразу в третий класс. Об учителях этой школы он всегда вспоминал с большой теплотой и благодарностью. Эта школа, созданная на базе бьвшей гимназии и сохранившая во многом старые кадры, сумела перенести вьпавшие на долю общеобразовательных школ эксперименты, такие, как бригадньй метод обучения, тестирование учеников на будущую специальность и многое другое. И выпускники этой школы получали добротные знания, и многие из них стали в дальнейшем известными квалифицированными специалистами. Алексей Георгиевич часто вспоминал, что в школе была создана атмосфера доброжелательности и взаимопомощи, что особенно помогало детям, в чьи семьи пришла беда.

После окончания школы в 1939 году Алексей Георгиевич поступил в Московский университет на отделение математики механико-математического факультета. Годы учебы пришлись на тяжелое для страны время - в 1941 году началась Великая Отечественная война. Учеба вынужденно прерьвалась, и университет был окончен им в 1946 году. В том же году он поступил в аспирантуру научно-исследовательского Института математики Московского государственного 
университета. Начало формирования творческой личности Алексея Георгиевича происходило под влиянием Н. Н. Лузина, П. С. Александрова, А. Н. Колмогорова, А. О. Гельфонда, Б. В. Гнеденко, В. В. Степанова, А. Я. Хинчина и других. В 1949 году он защитил кандидатскую диссертацию "О дифференциальной независимости рядов Дирихле".

В 1950 году он был принят на работу в Математический институт им. В. А. Стеклова, в отдел теории чисел, возглавляемьй Иваном Матвеевичем Виноградовым. И здесь следует указать, что влияние, которое оказал И. М. Виноградов на дальнейший творческий рост Алексея Георгиевича, на далшнейшее становление его как личности, переоценить невозможно. Для Алексея Георгиевича началась жизнь, неотделимая от жизни Математического института, началась его активная и плодотворная научная работа. Как известно, послевоенные годы - годы болшшого подъема науки в нашей стране. Формировались новые научные коллективы. Шла совместная научная работа различных математических школ. В этом русле можно рассматривать семинар Алексея Георгиевича в Математическом институте по методу тригонометрических сумм. Начался тесньй научный и дружеский контакт Алексея Георгиевича с ленинградской школой теории чисел, особенно с группой Юрия Владимировича Линника и его учениками.

В середине 50-х годов работы Алексея Георгиевича по тригонометрическим сумма получили признание среди математиков. В 1955 году опубликована работа [10], где появилась знаменитая формула А. Г. Постникова о представлении характера Дирихле по модулю, равному степени простого числа, через экспоненту от многочлена, и тем самьг задача об оценке сумм характеров была сведена к оценкам тригонометрических сумм $Г$. Вейля. Первыми ее услышали И. М. Виноградов и Ю. В. Линник и побудили А. Г. Постникова перейти к оформлению докторской диссертации. Отметим, что эту формулу теперь называют формулой Постникова. Она легла в основу целого направления в аналитической теории чисел. В 1956 году Алексей Георгиевич защитил докторскую диссертацию "Исследование по методу тригонометрических сумм И.М. Виноградова".

Результаты его научной деятельности опубликованы в более, чем пятидесяти статьях и четырех монографиях: “Арифметическое моделирование случайных процессов" (1960), "Эргодические вопросы теории сравнений и теории диофантовых приближений" (1966), "Введение в аналитическую теорию чисел” (1971), “Тауберова теория и ее применения” (1979).

Научная деятельность Алексея Георгиевича началась с исследования дифференциально-разностной независимости рядов Дирихле. Эта тема продолжает и обобщает теорему Д. Гилберта о дифференциальной независимости дзета-функции Римана.

В работах "О структуре двумерных диофантовых приближений", "Остаточный член в тауберовой теореме Харди-Литтлвуда", "Упрощение элементарного доказательства А. Сельберга асимптотического закона распределения простых чисел" можно увидеть, как Алексей Георгиевич ищет область приложения своих сил и поле своих интересов, а начиная с работ "О сумме характеров по модулю равно степени простого числа", "К вопросу о распределении дробных долей показательной функции", "Некоторые общие теоремы о равномерном распределении дробных долей" его математические вкусы определились.

В теории равномерного распределения дробных долей показательной функции метод Виноградова оценок сумм $\Gamma$. Вейля распространяется на суммы с показательной функцией в экспоненте. Получен критерий для равномерного распределения дробных долей показательной функции в гауссовом поле [23].

Следующий цикл работ А.Г. Постникова относится к нормальным по Бернулли и Маркову последовательностям знаков при записи числа в позиционной системе счисления.

Центральным резултатом здесь является найденный им признак равномерного распределения по модулю единица [21] и критерий вполне равномерно распределенной последовательности [27].

Особое место в творчестве Алексея Георгиевича занимают теоремш абелева и тауберова типа [4], [8], [9].

Здесь Алексей Георгиевич первым стал рассматривать теоремы тауберова типа в комплексной области с остаточным членом.

Большое число работ А. Г. Постникова посвящено вероятностной теории чисел. Один из первых резултатов - вариант известной теоремы Деланжа с остаточньм членом [47].

В теории вероятностей часто рассматриваются задачи об оценке функции концентрации и 
максималњной вероятности для сумм независимых векторов.

Используя методы геометрии чисел, в работах [54], [56] были получены улучшение оценки для функции концентрации и новая оценка для максимальной вероятности целочисленных независимых случайных векторов, которая явно учитьвает параметры распределения слагаемых.

Математики, сотрудничавшие с Алексеем Георгиевичем на семинарах, конференциях, его ученики хорошо помнят, как он всегда с глубоким интересом относился к резулштатам, где теория чисел использовалась в других областях математики, и наоборот, где методы других наук давали возможность получить новые результаты в теории чисел. Эргодическая теория, теория вероятностей, моделирование случайных последовательностей - области, в которых такие применения им были найдены. А. Г. Постников постоянно подчеркивал аналогии между теорией чисел и анализом. Эти аналогии составляют методическую основу для применения методов теории вероятностей к изучению распределения значений арифометических функций.

\begin{tabular}{|c|c|}
\hline Теория чисел & Анализ \\
\hline Натуральньй ряд чисел & Отрезок $[0,1]$ вещественной оси \\
\hline Арифметическая прогрессия & Полуотрезок $\left[\frac{a}{D}, \frac{a+1}{D}\right)$ \\
с модулем $D$ & Мера Лебега множества \\
\hline Асимптотическая плотность & чисел отрезка $[0,1]$ \\
множества $M$ натуральных чисел & \\
$D(M)=\lim _{N \rightarrow \infty} \frac{1}{N} \sum_{n \leqslant N, n \in M} 1$ & Интегралшная сумма \\
\hline Сумма $\frac{1}{N} \sum_{n=1}^{N} f(n)$ & \\
функции $f(x)$, заданной & Кусочно постоянная \\
на отрезке $[0,1]$ & на полуотрезках \\
Периодическая с цельм & {$\left[\frac{a}{D}, \frac{a+1}{D}\right]$ функция } \\
периодом $D$ функция & \\
натурального аргумента &
\end{tabular}

Начиная с 1953 г. по инициативе И. М. Виноградова Алексей Георгиевич активно занимался поиском элементарного доказательства оценки Хассе-А. Вейля суммы характеров от многочлена. Эти поиски привели к новому методу оценок упомянутых сумм. В 1967 г. после Всесоюзной школы по теории чисел в г. Душанбе Алексей Георгиевич элементарно доказал теорему об оценке снизу количества решений эллиптического сравнения по простому модулю. Предложенный метод А. Г. Постникова нашел далшнейшее развитие в трудах отечественных и зарубежных математиков.

Алексей Георгиевич принимал самое активное участиев организации и проведении школ, конференций, съездов и другой научно-организационной работе.

Большое внимание он уделял научно-педагогической работе, отдавая много сил и энергии руководству аспирантами и стажерами, чтению лекций и проведению семинаров, как в МИАНе, так и в ряде университетов (Саратов, Казань, Алма-Ата, Вильнюс и др.).

Среди его учеников доктора и кандидаты наук. Алексей Георгиевич бескорыстно помогал людям.

В общении с людьми его отличала доброжелательность. У Алексея Георгиевича учились видеть глубинные жизненные течения, учились преданности истине.

Светлая память об Алексее Георгиевиче Постникове навсегда останется в наших сердцах.

В. С. Владимиров, А. А. Дезин, А. А. Карачуба, Л. Д. Кудрявцев, М. П. Минеев, С. М. Никольский, Л.П. Постникова,

Ю. В. Прохоров, В.Н. Чубариков, А.Б. Шидловский, А. А. Юдин

\section{СПИСОК ПУБЛИКАЦИЙ А. Г. ПОСТНИКОВА}

[1] О дифференциалной независимости рядов Дирихле // Докл. АН СССР. 1949. Т. 66. № 4. C. $561-564$

[2] О дифференциальной независимости рядов Дирихле // Кандидатская диссертация (рукопись). М.: МГУ, 1949 
[3] О структуре двумерных диофантовых приближений // Докл. АН СССР. 1951. Т. 76. № 4. C. $493-496$

[4] Остаточный член в тауберовой теореме Харди и Литтлвуда // Докл. АН СССР. 1951. T. 77. № 2. C. $193-196$

[5] О некоторых тригонометрических неравенствах // Докл. АН СССР. 1951. Т. 81. № 4. C. 501-504

[6] Некоторые общие теоремы о равномерном распределении дробных долей // Докл. АН CССР. 1952. Т. 84. № 2. С. 217-220 (совм. с Н. М. Коробовым)

[7] $\mathrm{K}$ вопросу о распределении дробных долей показательной функции // Докл. АН СССР. 1952. T. 86. № 3. C. $473-476$

[8] Тауберова теорема для рядов Дирихле // Докл. АН СССР. 1953. Т. 92. № 3. С. 487-490

[9] Общая теорема абелева типа для степенного ряда // Докл. АН СССР. 1954. Т. 96. № 5. C. $913-916$

[10] О сумме характеров по модулю равному степени простого числа // Изв. АН СССР. Сер. матем. 1955. Т. 19. № 1. С. 11-16

[11] Об одном применении централшной предельной теоремы теории вероятностей // УМН. 1955. T. 10. № 1. C. $147-149$

[12] Упрощение элементарного доказательства А. Сельберга асимптотического закона распределения простых чисел // УМН. 1955. Т. 10. № 4. С. 75-87 (совм. с Н. Р. Романовым)

[13] Свойства решений диофантовых неравенств в поле формальных степенных рядов // Докл. AH CCCP. 1956. T. 106. № 1. C. 21-22

[14] Обобщение одной из задач Гильберта // Докл. АН СССР. 1956. Т. 107. № 4. С. 512-515

[15] Аддитивные задачи с растущим числом слагаемых // Докл. АН СССР. 1956. Т. 108. № 3. C. 392

[16] Оценка показательной тригонометрической суммы // Изв. АН СССР. Сер. матем. 1956. T. 20. № 5. C. $661-666$

[17] Аддитивные задачи с растущим числом слагаемых // Изв. АН СССР. Сер. матем. 1956. T. 20. № 6. C. $751-764$

[18] Свойства решений диофантовых неравенств в поле формалшных степенных рядов // Матем. сб. 1956. Т. 40. № 3. С. 295-302

[19] Generalization of one of the Hilbert problems // J. Indian Math. Soc. 1956. V. 20. № 1-3. P. 207-216

[20] On Dirichlet $L$-series with the character modulus equal to the power of a prime number // J. Indian Math. Soc. 1956. V. 20. № 1-3. P. 217-226

[21] Исследования по методу тригонометрических сумм И. М. Виноградова // Докторская диссертация (рукопись), 1956

[22] Нормальные по Бернулли последовательности знаков // Изв. АН СССР. Сер. матем. 1957. Т. 21. № 4. С. 501-514 (совм. с И. И. Пятецким)

[23] Критерий равномерного распределения показателшной функции в комплексной области // Вестн. ЛГУ. Серия матем., мех., астр. 1957. Т. 13. № 3. С. 81-88

[24] Нормальная по Маркову последовательность знаков и нормальная цепная дробь // Изв. АН СССР. Сер. матем. 1957. Т. 21. № 6. С. 729-746 (совм. с И. И. Пятецким)

[25] Критерий для вполне равномерно распределенной последовательности // Докл. АН СССР. 1958. T. 120. № 5. С. 973-975

[26] Об упаковке в большой куб шаров двух сортов // Научные Докл. Высшей школы. Физ.-матем. науки. 1958. № 1. С. 25-27

[27] Усиленньй закон болших чисел для выборки из равномерно распределенной случайной величины // Изв. АН СССР. Сер. матем. 1958. Т. 22. № 3. С. 433-438

[28] Решение системы конечно-разностных уравнений, соответствующих задаче Дирихле, с помощью нормальной последовательности знаков // Докл. АН СССР. 1958. Т. 123. № 3. C. $407-409$

[29] Ein Analogon des Tarryschen Problems für die Exponential funktion // Sammelband zu Ehren des 250 Geburtstages Leonhard Eulers. Berlin: Akademie-Verlag, 1959. P. 281-283

[30] Аддитивные задачи с растущим числом слагаемых // Българска Академия на науките. Известия на Матем. институт. 1959. Т. 4. № 1. С. 73-77 
[31] Исследование коротких рациональных тригонометрических сумм // Българска Академия на науките. Известия на Матем. институт. 1959. Т. 4. № 1. С. 81-85

[32] Арифметическое моделирование случайных процессов // Труды МИАН. 1960. Т. 57

[33] Об очень короткой показательной рациональной тригонометрической сумме // Докл. АН CCCP. 1960. T. 133. №6. С. 1298-1299

[34] О количестве попаданий дробных долей показательной функции на данньй интервал // УМH. 1961. T. 16. № 3. С. 201-205

[35] К семидесятилетию Ивана Матвеевича Виноградова // Изв. АН СССР. Сер. матем. 1961. T. 25. № 5. C. $621-628$

[36] Иван Матвеевич Виноградов (к семидесятилетию со дня рождения) // УМН. 1962. Т. 17. № 2. С. 201-214 (совм. с Ю. В. Линником)

[37] Динамические системы в теории чисел // Труды 4-ого Всесоюзного Математического Съезда. Секционные доклады. Ленинград, 3-12, Июля 1961. Т. 11. Л.: Наука, 1964. С. 124-131

[38] Эргодические вопросы теории диофантовых приближений // Труды МИАН. 1966. Т. 82

[39] Всесоюзная школа по метрической теории чисел // УМН. 1966. Т. 21. № 1 (127). С. 201-204 (совм. с К. Ю. Булота)

[40] О состоянии и основных направлениях развития исследований в области аналитической теории чисел // УМН. 1967. Т. 22. №1. С. 3-14 (совм. с И. М. Виноградовым)

[41] Мир // Труды Международного Конгресса математиков. Москва, 1966. М., 1968. С. 163-176 (совм. с И.М. Виноградовым)

[42] Введение в аналитическую теорию чисел. М.: Наука, 1971

[43] О числе решений одного сравнения // Acta Arithmetica. 1972. V. 21. P. 103-110 (with Г.И. Перельмутером)

[44] Об асимптотических свойствах собственных функций оператора Лапласа // Mathematica. 1973. T. 15 (38). №1. C. 101-118

[45] Школа “Аналитическая теория чисел" // УМН. 1973. Т. 28. № 3 (171). С. 240-241

[46] Вероятностная теория чисел // Знание (отдельная брошюра). 1974. № 3

[47] О теореме Деланжа // Сборник “Актуалшные проблемы аналитической теории чисел". Минск: Наука и Техника, 1974. С. 168-177

[48] Култура занятий математикой (Из записок ученого) // Знание (отделшная брошюра). 1975. № 7

[49] Новое доказательство теоремы Халаса в регулярном случае // Лит. матем. сб. 1975. Т. 15. № 3. С. 201-210 (совм. с 3. М. Юшкисом)

[50] К теории сумм Якобсталя // Труды МИАН. 1976. Т. 142. С. 208-214 (совм. с С. А. Степановым)

[51] Локальная предельная теорема для распределения дробных долей показательной функции // Теория вероятн. и ее примен. 1978. Т. 23. № 3. С. 540-547 (совм. с Д. А. Москвиным)

[52] Новый вьвод формулы для числа классов бинарных квадратичных форм отрицательного определителя в функциональном случае // Труды МИАН. 1978. Т. 148. С. 195-200

[53] Тауберова теория и ее применения // Труды МИАН. 1979. Т. 144

[54] Об оценке функции концентрации для суммы одинаково распределенных двумерных целочисленных независимых случайных векторов // Теория вероятн. и ее примен. 1981. Т. 26. № 1. С. 156-160 (совм. с А.А. Юдиным)

[55] Об одной точной формуле в теории чисел // Матем. заметки. 1984. Т. 35. №6. С. 785-787

[56] Оценка максимальной вероятности для суммы независимых векторов // Теория вероятн. и ее примен. 1987. Т. 2. С. 358-361 (совм. с А. А. Юдиньпм)

[57] Introduction to Analytic Number Theory: Amer. Math. Soc., 1985

[58] О существовании рациональных точек на кривой над простым конечным полем // Исследования по теории чисел. № 10. Саратов: Изд-во Саратовского ун-та, 1988. С. 4-8 (совм. с Н.М. Глазуновьгм) 